\title{
PENDAMPINGAN BELAJAR DARI RUMAH BAGI ANAK KELAS 7,8,9 SMP DAN KELAS 10 SMA DIMASA PANDEMI COVID 19 DI HKBP DUREN JAYA BEKASI
}

\author{
Hotmaulina Sihotang ${ }^{\star 1}$, Manahan Tampubolon ${ }^{2}$, Bernadetha Nadeak ${ }^{3}$, \\ Rospita A. Siregar ${ }^{4}$, Cheri Surina Ita ${ }^{5}$ \\ 1,2,3,4,5 Universitas Kristen Indonesia, Jakarta, Indonesia \\ E-mail: hotmaulina.sihotang@uki.ac.id; manahan tb@yahoo.com; \\ bernadetha.nadeak@uki.ac.id; rospita.siregar@uki.ac.id; cheri.ita@bpkpenaburjakarta.or.id
}

\begin{abstract}
Abstrak
Pengabdian kepada Masyarakat di HKBP Duren Jaya merupakan implementasi dan keberlanjutan MoU antara Universitas Kristen Indonesia (UKI) dengan HKBP Duren Jaya tahun 2020. Pandemi Covid-19 diumumkan di Indonesia 2 Maret 2020 sampai saat ini berdampak bagi semua sektor termasuk sektor pendidikan yang mengakibatkan siswa belajar dari rumah (BDR). Orangtua dan siswa banyak mengalami hambatan selama belajar dari rumah maka PkM memilih topik berkaitan dengan kebutuhan jemaat. PkM bertujuan memberikan peningkatan pemahaman dan pengetahuan model pendampingan belajar bagi orangtua dan taktik belajar efektif bagi siswa dan kelas 10 SMA. Metode PkM adalah seminar dan lomba membuat video model pendampingan orangtua selama anak belajar dari rumah. Penilaian video menggunakan indikator. Hasil PkM sangat menggembirakan ditunjukkan dengan kesungguhan panitia dari gereja mengurus kegiatan dengan maksimal dengan tetap menerapkan prokes yang ketat, partisipasi bertanya saat seminar, video model pendampingan orangtua saat anak belajar di rumah yang dapat menjadi contoh bagi orangtua dan anak.
\end{abstract}

Kata kunci: Peran orangtua; belajar efektif; belajar dari rumah

\begin{abstract}
Community Service (PkM) at HKBP Duren Jaya is the implementation and continuation of the MoU between Universitas Kristen Indonesia (UKI) and HKBP Duren Jaya in 2020. The Covid19 pandemic has affected all sectors including the education sector, which resulted the students were learning from home. Parents and students have been experiencing many obstacles while studying from home, so PkM has chosen topics related to the needs of the congregation. PkM aims to provide increased understanding and knowledge of learning mentoring models for parents and effective learning tactics for students in junior high school and grade 10 of high school. The PkM method is a seminar and competition to make a video model of parental assistance while the children study from home. Video assessment uses indicators by evaluators. The results of the PkM are very encouraging, as shown by the seriousness of the committee from the church to optimally manage activities by still implementing health procedures strictly, active participating the seminar by asking several questions, video models of parenting assistance while the children study at home that can be a model for parents and children.
\end{abstract}

Keywords: The role of parents; effective learning; study from home 


\section{PENDAHULUAN}

HKBP Duren Jaya berada di Kelurahan Duren Jaya, Kecamatan Bekasi Timur Kota Bekasi sekitar 23 $\mathrm{Km}$ dari Universitas Kristen Indonesia. HKBP Duren Jaya memiliki jemaat sekitar 550 KK . Saat ini di Indonesia khususnya di Bekasi terkena dampak pandemi Covid 19 dalam semua bidang. Pandemi Covid-19 ini sudah banyak memengaruhi dan mengancam berbagai bidang, khususnya pendidikan.

Sampai saat ini, meskipun sudah diterapkan adanya era adaptasi kebiasaan baru atau new normal dan beberapa sektor sudah melakukan aktivitas kembali dengan memperhatikan protokol kesehatan, namun dalam bidang pendidikan masih belum melakukan aktivitas seperti biasa dan masih menggunakan pembelajaran secara daring atau dikenal dengan belajar dari rumah (DBR). Semua jenjang pendidikan di Bekasi mulai dari PAUD, SD, SMP, SMA/SMK, Perguruan Tinggi melakukan pembelajaran secara daring. Pembelajaran daring merupakan salah satu kebijakan dari pemerintah untuk berupaya memutus mata rantai pandemi Covid-19 di Indonesia. Sistem pembelajaran daring (dalam jaringan) merupakan sistem pembelajaran tanpa tatap muka secara langsung antara guru dan siswa tetapi dilakukan secara online memanfaatkan jaringan internet (syncronous). Pembelajaran secara daring merupakan implementasi kebijakan Menteri Pendidikan dan Kebudayaan terkait Surat Edaran Nomor 4 Tahun 2020 tentang Pelaksanaan Kebijakan Pendidikan dalam Masa Darurat Penyebaran Covid-19. Berbagai media pembelajaran jarak jauh digunakan dalam mendukung pembelajaran melalui jaringan online sesuai dengan platform yang dimiliki satuan pendidikan agar pembelajaran tetap berjalan dalam waktu yang bersamaan, meskipun di tempat yang berbeda. Dalam pelaksanaan pembelajaran secara daring tentunya menimbulkan dampak yang dirasakan baik dari guru, peserta didik, bahkan sampai orang tua. Sesuai dengan kebutuhan gereja maka PkM semester genap TA 2020/2021 difokuskan pada seminar bagi orangtua dan anak sekolah minggu dan remaja agar senang belajar yang didampingi orangtua di rumah.

Gereja HKBP Duren Jaya berfugsi sebagai agen transformasi ditengah masyarakat mencakup upaya 
melakukan tugas panggilan, mendukung dan membantu jemaat yang mengalami dampak Covid 19. Seksi Diakonia membuat program pendampingan (nurturing) bagi jemaat terlebih pada tahun pemberdayaan pihak gereja memberdayakan semua pihak termasuk mitra kerjasama yakni Program Pascasarjana UKI. PPs UKI telah melakukan kerjasama dengan HKBP Duren Jaya tahun 2020. Kegiatan PkM dilakukan secara berkesinambungan. PPs UKI dalam pelaksanaan tridharma hadir untuk membantu masyarakat sehingga dapat meningkatkan kualitas sumber daya manusia.

\section{METODE PELAKSANAAN}

Metode PkM adalah (a) penyuluhan yang bertujuan untuk memberikan pemahaman bagi orangtua tentang pengembangan etika kristiani dan implementasinya, pemahaman dan cara mengatasi masalah PJJ yang dihadapi orangtua dan anak selama belajar dari rumah/PJJ, (b) difusi Ipteks dengan membuat video model pendampingan orangtua selama belajar dari rumah dengan menjelaskan indikator video. Peserta sebanyak 69 orang, yang terdiri dari 40 siswa kelas 7,8,9 SMP dan kelas 10 SMA dan 29 orangtua dan panitia Tahun Pemberdayaan HKBP Duren Jaya. Penilaian video model pendampingan menggunakan indikator yang kami sajikan dalam tabel 1. Tim penilai video tiga orang yang terdiri dari 2 orang unsur dari pihak gereja dan 1 orang dari tim PkM UKI

Tabel 1. Indikator Penilaian Video Model Pembelajaran

\begin{tabular}{|l|l|l|l|l|l|}
\hline No & Indikator & \multicolumn{3}{|c|}{ Diskripsi penilaian } \\
\cline { 3 - 6 } & Kekompakan & $\begin{array}{l}\text { Interaksi antara anak } \\
\text { dan orang tua sangat } \\
\text { jarang }\end{array}$ & $\begin{array}{l}\text { Ada interaksi } \\
\text { antara anak dan } \\
\text { orang tua sesekali } \\
\text { saja }\end{array}$ & $\begin{array}{l}\text { Ada interkasi } \\
\text { yang didominasi } \\
\text { oleh anak atau } \\
\text { orang tua }\end{array}$ & $\begin{array}{l}\text { Ada interkasi } \\
\text { yang baik, } \\
\text { harmonis antara } \\
\text { anak dan orang } \\
\text { tua }\end{array}$ \\
\hline 2 & Kreativitas video & $\begin{array}{l}\text { Ada proses editing, } \\
\text { tidak mempunyai nilai } \\
\text { interaktif yang menarik } \\
\text { dan keseluruhan tidak } \\
\text { terlihat keseruannya }\end{array}$ & $\begin{array}{l}\text { Ada proses } \\
\text { editing, sudah ada } \\
\text { nilai interaktif } \\
\text { menarik sesekali, } \\
\text { dan keseluruhan } \\
\text { tidak terlihat } \\
\text { keseruannya }\end{array}$ & $\begin{array}{l}\text { Ada proses } \\
\text { editing, dan sudah } \\
\text { ada interaktif } \\
\text { menarik, dan } \\
\text { keseluruhan } \\
\text { belum terlihat } \\
\text { keseruannya }\end{array}$ & $\begin{array}{l}\text { Ada proses } \\
\text { editing, } \\
\text { mempunyai } \\
\text { nilai interaktif } \\
\text { menarik dan } \\
\text { keseluruhan } \\
\text { terlihat } \\
\text { keseruannya }\end{array}$ \\
\hline 3 & $\begin{array}{l}\text { Isi video : } \\
\text { akademik }\end{array}$ & $\begin{array}{l}\text { Isi video kurang } \\
\text { memuat makna yang } \\
\text { mengandung kegiatan } \\
\text { akademik tidak }\end{array}$ & $\begin{array}{l}\text { Isi video memuat } \\
\text { makna yang } \\
\text { mengandung } \\
\text { kegiatan }\end{array}$ & $\begin{array}{l}\text { Isi video memuat } \\
\text { makna yang } \\
\text { mengandung } \\
\text { kegiatan }\end{array}$ & $\begin{array}{l}\text { Isi video } \\
\text { memuat makna } \\
\text { yang } \\
\text { mengandung }\end{array}$ \\
\hline
\end{tabular}




\begin{tabular}{|l|l|l|l|l|l|}
\hline & & $\begin{array}{l}\text { beruntun, tidak } \\
\text { sistematik dan tidak } \\
\text { menarik }\end{array}$ & $\begin{array}{l}\text { akademik, tetapi } \\
\text { tidak beruntun, } \\
\text { tidak sistematik } \\
\text { dan tidak menarik } \\
\text { tuntas dan } \\
\text { sistematik tetapi } \\
\text { belum menarik }\end{array}$ & $\begin{array}{l}\text { kegiatan } \\
\text { akademik sudah } \\
\text { beruntun, sudah } \\
\text { sistematik dan } \\
\text { menarik }\end{array}$ \\
\hline 4 & $\begin{array}{l}\text { Isi video : non } \\
\text { akademik (gerak } \\
\text { dan lagu, } \\
\text { backsound, } \\
\text { menggunakan } \\
\text { properties, dll) }\end{array}$ & $\begin{array}{l}\text { Isi video kurang } \\
\text { memuat kegiatan non } \\
\text { akademik, dan terlihat } \\
\text { monoton saja }\end{array}$ & $\begin{array}{l}\text { Isi video memuat } \\
\text { hanya 1 kegiatan } \\
\text { non akademik }\end{array}$ & $\begin{array}{l}\text { Isi video memuat } \\
\text { hanya 2 kegiatan } \\
\text { non akademik }\end{array}$ & $\begin{array}{l}\text { Isi video } \\
\text { memuat 3 } \\
\text { kegiatan non } \\
\text { akademik }\end{array}$ \\
\hline
\end{tabular}

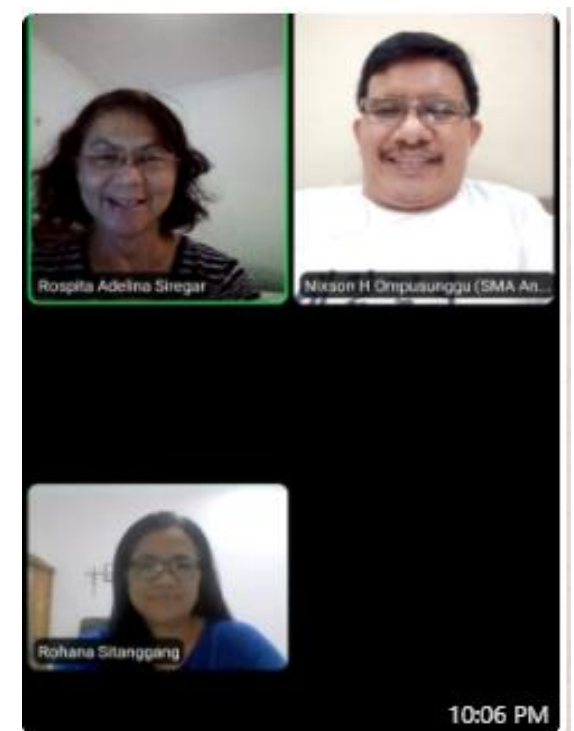

Gambar 1. Dewan juri

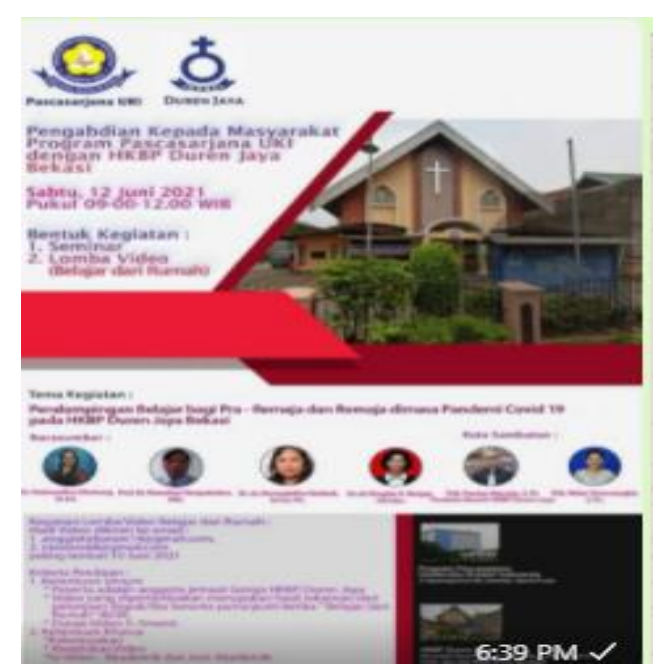

Gambar 2 Flyer PKM

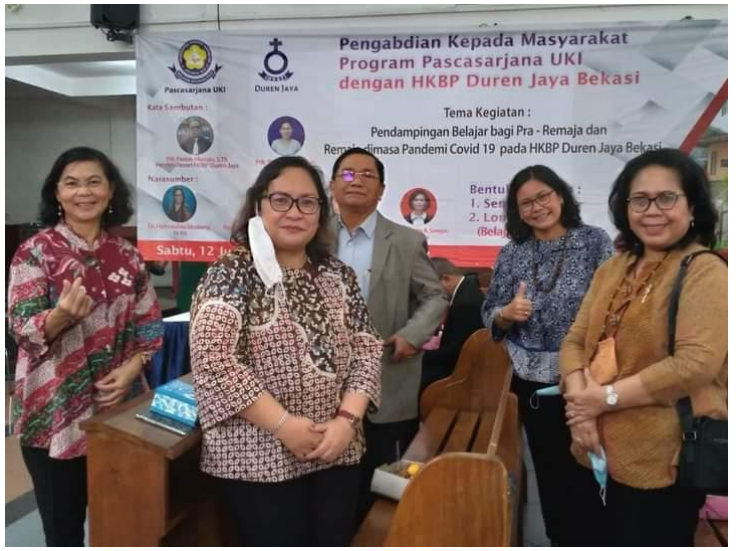

Gambar 3 Fasilitator PkM Dosen dan Mahasiswa

Analisis menggunakan analisis deskriptif. Luaran PkM selain publikasi ini juga berupa publikasi pada media online warta kota

https://wartakota.tribunnews.com/2021/06 /13/video-pascasarjana-uki-gelar-pkmberdayakan-orangtua-dalam-pji dan youtube https://youtu.be/8-PMw1A5nQc.

\section{HASIL DAN PEMBAHASAN}

1. Peran orangtua dalam pendampingan belajar dari rumah anak kelas 7,8,9 SMP dan kelas 10 SMA.

Seminar dilaksanakan pkl 9 setelah didahului ibadah dalam dua tempat dengan live streamning. Hal ini dilakukan 
karena kita menerapkan protokol kesehatan. Kelompok orang tua berada dalam ruang gereja dengan nara sumber Prof. Dr Manahan, MM; Dr. Hotmaulina Sihotang, M.Pd dan Dr. dr. Rospita Siregar, MH.Kes dengan moderator St. Rohana Sitanggang, MM. Sedangkan Tampubolon. Kelompok anak berada di aula gereja dengan narasumber Dr.dr. Bernadetha Nadeak, M.Pd, PA dan moderator Cheri mahasiswa MAP.

Hasil seminar menunjukkan kesungguhan dari peserta aktif bertanya karena memang orangtua mengalami kesulitan mendampingi anak. Kesulitan yang dihadapi orangtua adalah kurang paham materi pelajaran SMP dan SMA; kurang menguasai teknologi untuk mencari materi tambahan dari internet; kesulitan mengatur bentuk pendampingan karena anak ada SD, SMP, dan SMA; PR banyak sehingga anak belajar sampai pkl 3 pagi.

Hal ini sejalan dengan hasil survey Tanoto Foundation (Kompas.com, 15 Nov 2020) ditemukan (a) orangtua $56 \%$, orang tua mengaku kurang sabar dan jenuh menangani kemampuan dan konsentrasi anak yang duduk di bangku SD/MI dan 34\% di bangku SMP/MTs.

(b) $19 \%$ orang tua kesulitan menjelaskan materi pelajaran ke anak untuk SD/MI dan $28 \%$ untuk SMP/MTs (c) $15 \%$ orang tua kesulitan memahami materi pelajaran anak untuk SD/Ml dan $24 \%$ untuk SMP/MTs. Hal yang hampir sama (Kemendikbud, 2020) hasil temuan, yakni tidak memiliki akses internet 32\%, tidak memahami materi pelajaran $34 \%$, Gagap teknologi (gaptek) 19\%, dan 15\% lainnya.

Untuk mengatasi masalah yang dihadapi orangtua memang tidak mudah karena mempelajari materi SMP dan SMA tidak mampu orangtua maka solusinya alternatif orangtua mau belajar mengupdate pengetahuan melalui mencari materi melalui internet. Jika materi tidak mampu paling tidak mendampingi anak agar tidak merasa tertekan. Selain itu alternatif lain mengikutsertakan anak ikut bimbingan belajar online. Narasumber mengatakan untuk mengatur waktu yang utama adalah delapan jam istirahat/tidur selebihnya mengatur jam belajar sesuai jam sekolah dan membuat kesepakatan dengan anak mengatur kegiatan lainnya.

Orang tua pada awalnya berperan dalam membimbing sikap serta keterampilan yang mendasar, seperti pendidikan agama untuk patuh terhadap aturan, dan untuk pembiasaan yang baik (Nurlaeni \& Juniarti, 2017), namun perannya menjadi meluas yaitu sebagai pendamping pendidikan 
akademik. Prabhawani (2016) menyatakan bahwa pelaksanaan pendidikan merupakan tanggung jawab orang tua dan masyarakat sekitar tidak hanya tanggung jawab sekolah saja. Mendampingi anak ketika belajar adalah sesuatu yang sangat penting bagi anak yaitu dapat membangun kedekatan antara orang tua dengan anak, belajar mengajaknya berdiskusi agar mengetahui bagaimana pola berpikir anak. Adapun Peran penting orang tua dalam mendampingi anak yaitu (Sundari \& Yoridho, 2018), sebagai berikut:

1. Anak merasa tidak sendiri

2. Orangtua pemberi semangat

3. Memfasilitasi kebutuhan anak

4. Tempat berdiskusi dan bertanya

5. Membantu mengenali diri sendiri

6. Melihat dan mengembangkan bakat anak.

7. Menciptakan lingkungan kondusif belajar

Di akhir sesi seminar, narasumber menanyangkan hasil video model pendampingan orangtua selama anak belajar dari rumah. Video yang masuk nominasi ada delapan. Penilaian video berdasarkan indikator yakni kekompakan tim, (2) kreativitas, (3) isi video muatan akademik, (4) isivideo muatan non akademik. Secara teoritis skor maksimal 54. Hasil penilaian dewan juri tiga yang terbaik adalah sebagai berikut: terbaik pertama dengan perolehan nilai 44 , terbaik kedua dengan nilai 36 dan terbaik ketiga dengan nilaia 35. Hasil penilaian dewan juru diumumkan memberikan semangat bagi orangtua dan anak. Hasil penilaian dewan juru tertera pada tabel 2.

\section{EVALUASI VIDEO BDR}

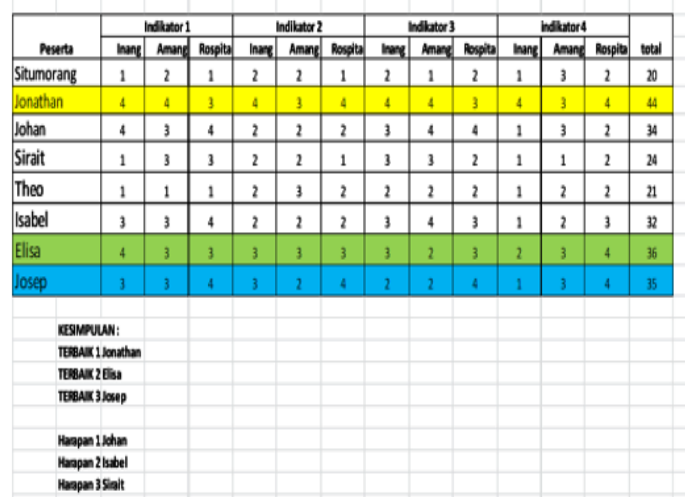

2. Kiat-Kiat belajar menyenangkan yang efektif dan efisien agar tetap berprestasi dimasa pandemi Covid19.

Kegiatan seminar dilakukan di HKBP Duren Jaya dengan jumlah peserta 69 orang remaja dengan Pendidikan sekolah menengah pertama dan sekolah menengah atas. Sebelum masuk dalam materi seminar, pemateri melakukan brainstorming tentang proses belajar daring yang selama hampir 3 semester sudah 
dijalani. Beragam pendapat di sampaikan oleh peserta, dan dapat disimpulkan bahwa mulai timbul kejenuhan, stress yang memicu emosi dan kemalasan pada siswa dalam situasi pandemik ini. Penyebab kejenuhan yang paling dirasakan adalah karena kesulitan memahami materi yang bersifat eksakta. Hampir $60 \%$ para guru di sekolah tidak memberikan panduan untuk memudahkan siswa memahami materi tersebut. Belum lagi banyaknya tugas yang harus dikerjakan. Kemudian emosi anak-anak menjadi tidak stabil ,dari yang biasanya belajar bersama, bermain bersama, melakukan kegiatan bersama kawan, sekarang tidak lagi dapat dilaksanakan. Anak menjadi kesepian dan harus melakukan segalanya sendiri. Hal ini membuat anak tidak fokus dalam menyelesaikan tugas sekolahnya.

Materi seminar yang diberikan adalah agar anak dapat mengenali gaya belajar mereka sehingga mereka nyaman dan focus menjalaninya. Selama ini anak hanya belajar dengan cara yang biasa, dan orangtuapun hanya mendampingi. Jika ada gaya atau metode belajar yang bukan semestinya misalnya anak belajar sambil dengar musik atau nonton TV, maka orangtua tidak menyetujuinya dan cenderung melarang. Dan ini dapat membuat anak menjadi marah dan tidak mau belajar.

Dari beberapa teori dan penelitian yang dilakukan, terdapat pengaruh yang signifikan gaya belajar seseorang dengan peningkatan prestasi (Ardianik,2017). Menurut Deporter dkk (2011) mengatakan gaya belajar merupakan kecenderungan siswa untuk mempunyai strategi tertentu dalam belajarnya, sehingga mereka bertanggungjawab terhadap tuntutan dari tujuan belajar tersebut. Gaya belajar visual yang mengandalkan cara belajar dengan cara melihat, gaya belajar Auditory yaitu cara belajar dengan cara mendengar dan gaya belajar kinestetik, dimana anak belajar dengan cara bergerak, bekerja atau menyentuh, adalah gaya belajar yang harus diketahui dan dikenal siswa sebagai gayanya dalam belajar. Pemateri menjelaskan dengan menggunakan video dan dari 69 peserta yang hadir, tidak seorangpun yang memahami bagaimana gaya belajar mereka masing-masing. Mereka belajar seperti yang biasa dilakukan.dan membuat mereka menjadi malas dan tidak focus Ketika harus menjalaninya sendiri. 
Selanjutnya dilakukan test pada peserta agar secara cepat mereka dapat mengetahui gaya belajarnya masing-masing. Hasil test menunjukkan kecenderungan peserta lebih 50\% menyukai gaya belajar auditory dimana dengan mendengar akan lebih mudah dipahami. Misalnya belajar sambil mendengarkan musik, atau belajar sambil bersuara. Kemudian hasil test kami sampaikan pada peserta dan meminta agar peserta membicarakannya pada orangtua sehingga ada kesepahaman tentang gaya belajar anak. Orangtua tidak boleh marah ketika anak melakukan proses belajarnya sesuai dengan gayanya.

Disamping gaya belajar, maka pemateri juga menjelaskan bagaimana metode belajar yang menyenangkan seperti membuat peta konsep, juga peserta diajarkan bagaimana membuat jadwal belajar dengan kreatif, dan bagaimana membagi waktu antara belajar dan kegiatan hobby lainnya, juga bagaimana cara agar tetap fokus ketika belajar, yaitu dengan melakukan gerakan senam otak. Akhir dari seminar belajar efektif ini adalah peserta di berikan motivasi untuk dapat menghargai setiap capaian yang mereka dapatkannya.

\section{SIMPULAN}

Kegiatan Pengabdian kepada Masyarakat yang dilaksanakan di HKBP Duren Jaya Bekasi memberikan peningkatan pengetahuan kepada anak bagaimana teknik belajar PJJ efektif. Selain itu orangtua mengalami peningkatan pengetahuan tentang peran orangtua sebagai pendidik pertama dan utama serta memahami perlunya harmonisasi orangtua dengan anak.

\section{UCAPAN TERIMA KASIH}

PkM ini dapat kami laksanakan atas dukungan dari beberapa pihak. Oleh karena itu pada kesempatan ini kami menyampaikan terima kasih kepada yang terhormat dan terkasih: (1) Rektor UKI, Bapak Dr. Dhaniswara K. Harjono, SH, $\mathrm{MH}, \mathrm{MBA}$ atas dukungan dana UKI Ka. LPPM, Ibu Dr. Aartje Tehupeiory, SH., MH selaku Ka.LPPM, dan Pdt. Pantas Manalu, S.Th. selaku Pendeta Resort HKBP Duren Jaya, S,Th, Pdt Rittar Simorangkir, S.Th, Bapak Ir. J. Sitorus, Bapak Ir. Anggiat Sibarani dan seluruh panitia Tahun Pemberdayaan HKBP Duren Jaya telah membantu dan menyukseskan kegiatan PkM. 


\section{REFERENSI}

Ardianik (2017) , Analisis Proses berpikir siswa dalam memecahkan masalah ditinjau dari Gaya Belajar Siswa, https://repository.unitomo.ac.id/i d/id/ eprint/330

De Porter, B and Hernacky, M. 2011, Quantum learning membiasakan belajar nyaman dan menyenangkan; Penerjemah, Alwiyah Abdurrahman. Bandung; Kaifa

Nurlaeni, N., \& Juniarti, Y. (2017). Peran Orang Tua Dalam Mengembangkan Kemampuan Bahasa Pada Anak Usia 4-6 Tahun. Jurnal Pelita PAUD. https://doi.org/10.33222/pelitapa ud.v2i1.196

Prabhawani, S. W. (2016). Pelibatan Orang Tua Dalam Program Sekolah Di Tk Khalifah Wirobrajan Yogyakarta. Pendidikan Guru PAUD S-1.

Sundari, S., \& Yoridho, S. A. (2018). Langkah Kakiku Setelah SMA. Jakarta: Publicalnstitue Jakarta.

Surat Edaran Nomor 4 Tahun 2020 tentang Pelaksanaan Kebijakan Pendidikan dalam Masa Darurat Penyebaran Covid-19

Kompas.com, 15 November 2020 